\title{
Impact of Hospitalization and Dental Insurances on the Health Care Utilization in South Africa
}

\author{
Ernest Ouédraogo ${ }^{1^{*}}$ (D) Alou Dembélé (iD) and Justin Lwungili Bationo $^{3}$ (D) \\ ${ }^{1}$ Department of Economics and Management, University Thomas Sankara, Burkina Faso \\ ${ }^{2}$ Department of Agricultural Economics, Ankara University, Turkey \\ ${ }^{3}$ Department of Economics and Management, University Thomas Sankara, Burkina Faso
}

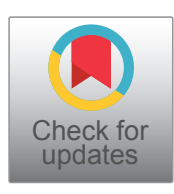

\begin{abstract}
Over this last decade, the South African government has implemented major health service reforms to move towards a universal system. With many questions surrounding the future of the healthcare system, it is important to understand the impact of health insurance on the demand for specialized health services. This paper investigates the impact of hospitalization and dental insurances on health care utilization. Using a nationally representative household survey, we apply a robust instrumental variable estimation to identify the causal impact of health insurances on health care utilization. We focus on both the likelihood of using each service and the intensity of utilization of this service as measured by the frequency of visits to a dentist for dental insurance and the number of nights spent in hospital for hospitalization insurance. Results show that having dental insurance coverage increases both the probability and frequency of visits to a dental professional. With respect to the insurance for hospitalization, results suggest that insurance reduces the probability of spending at least one night in hospital and the number of nights spent in hospital. A plausible explanation is that insurance holders are more likely to move towards better and faster care services. Therefore, policy makers and health care programmers in South Africa should improve individuals' access to both insurances to promote the use of these specific health services.
\end{abstract}

\section{Keywords}

Dental insurance, Hospitalization insurance, Healthcare, South Africa

\section{Introduction}

Health insurance aims to improve health care utilization and protecting households against impoverishment fromoutof-pocket expenditures expenditures [1-4]. Recently, healthcare has been attracting more and more attention in South Africa, with the government implementing major reforms to fix the ailing state system $[5,6]$. Yet, little empirical evidence exists on the impact of health insurance on the demand for specialized health service like dental care and hospitalization in South Africa. Various types of health insurance are available in South Africa from private to public, complete to partial insurance [1]. By reducing the cost of care, individual with insurance become more likely to consult the doctor than uninsured individuals $[4,7,8]$.

However, individuals are highly heterogeneous (age, health status, income, etc.), and the choice of whether to take an insurance is likely endogenous. In this case, the insured individuals may have characteristics that distinguish them from the uninsured individuals leading to a potential endogeneity issues $[9,10]$. Meer and Rosen [11] indicate that one of the major problems faced by most studies on the impact of insurance on health care consumption is endogenous bias. A variety of methods have been developed in the literature to overcome this difficulty, ranging from early studies based on a comparison of conditional means to more elaborate methods such as discontinuity regression, matching, simultaneous equation regression or the instrumental variable method [11-17]. This paper focuses on two important components of health insurance in South Africa: The dental and the hospitalization insurances which are barely studied in the literature. Dental insurance is designed to cover the expenses related to a visit to a dentist or dental treatment, while hospitalization insurance covers the charges for hospitalization services.

The aim this paper is to shed light on the impact of dental

*Corresponding author: Ernest Ouédraogo, Department of Economics and Management, University Thomas Sankara, Burkina Faso

Accepted: August 16, 2021

Published online: August 18, 2021

Citation: Ouédraogo E, Dembélé A, Bationo JL (2021) Impact of Hospitalization and Dental Insurances on the Health Care Utilization in South Africa. J Healthcare 4(1):77-83 
and hospitalization insurances on the demand for care in South Africa using a robust instrumental variables method. We rely on a twosteps econometric approach. First, we estimate the effect of insurance using standard Probit and Poisson models. Second, we estimate the effect using the instrumental variable method. After controlling for endogeneity, the results suggest that dental insurance increases the probability of consulting a dental professional by 40.21 percent. Hospital insurance reduces the probability of spending at least one night in hospital by 3.19 percent. Furthermore, our results suggest that the number of visits to the dental professional increase by 4.68 when they have dental insurance but spend less nights (a decrease of 7.54) in hospital if they have hospitalization insurance. The positive impact of dental insurance is in line with theoretical expectations. Moreover, the positive impact of hospital insurance confirms the empirical work of Hullegie and Klein [18] who find the same negative effect of hospital insurance. A plausible explanation is that insurance holders have a greater tendency to move towards better quality and faster care services and hospital insurance is often part of a larger care package in contrast to dental insurance.

The rest of the paper is structured as follows. Section 2 is devoted to a review of the theoretical and empirical literature on the effects of health insurance on the demand for care. Section 3 provides a summary descriptive analysis of the data and presents the empirical methodology while Section 4 reports the estimation results. Section 5 discusses the results and provides the overall conclusion and outlook.

\section{Literature Review}

Numerous theoretical and empirical works in health economics show a difference in the use of health services between insured and non-insured individuals [6]. These studies generally reveal a positive relationship between insurance and health care consumption [4]. Theoretically, health insurance affects agents' behavior through two main channels: First, by reducing the unit price of health services, health insurance is a subsidy for the purchase of medical care and thus affects the demand for care [2]. Two opportunistic behavior (ex-ante moral hazard and ex post moral hazard) can occur in the presence of health care insurance. The exante moral hazard results in the reduction of preventive costs (food, hygiene, security measures, etc.), which increases the risk of disease occurrence.

The ex post moral hazard appears, once the disease has occurred, by increasing the demand for medical care and the use of the most expensive services. Given the specificity of dental care and the generally very expensive hospitalization costs in South Africa, this effect is likely to be significant. Second, individual who are potentially ill or who anticipate high healthcare costs in the future have the strongest incentive to pay for insurance. In this case, adverse selection is observed because those who take out insurance are the most likely to use health services. Therefore, insurance is not random causing endogeneity issues. In this case, a simple estimation of the effect by comparison of means therefore leads to selection bias (linked to the non-random nature of the insurance allocation) and non-convergent estimators.
In a study in Cameroon, Ndongo and Nanfosso [13] confirm the presence of this selection effect by showing that good health status is negatively correlated with membership of a mutual health insurance scheme. Members of mutual health insurance are on average more frequently ill than nonmembers.

To assess the impact of health insurance on the consumption of health services, several empirical studies have been carried out indifferent countries. While most empirical studies confirm the potential of health insurance to increase the use of health services, the magnitude of the effect is often different depending on the robustness of the technique used. A first set of work on measuring the effect of health insurance was based essentially on a comparison of the averages of health care utilization between insured and non-insured. However, this technique is unsatisfactory because it ignores the endogeneity of the insurance choice. This, according to Levy and Meltzer (2001), leads to confuse the effect due to insurance with that of observable and unobservable characteristics of insured and non-insured. To test and correct for selection bias, Zounmenou [19] uses a simultaneous equation model to estimate the probability of subscribing to health insurance and using health services in Benin. The result reveals that private health insurance increases the probability of using health care by 0.33 percent. Salaheddine [20] combines a discontinuous regression technique and a matching method to assess the impacts of the insurance program on the health care utilization of rural poor participants in the Philippines. The author finds that the program had no effect on indigent households. This is mainly due to the lack of information and awareness among the indigent on their rights and benefits under the program. This finding is consistent with Schneider's (2004) finding that the PhilHealth program has had little impact on the use of health services by the indigent Filipino beneficiaries of the program.

To solve the problem of endogeneity, the most widely used method remains the instrumental variable method. Various instruments are used in the literature. Meer and Rosen [11] introduced employment status (self-employed or not) as an instrument of insurance choice to estimate the impact of health insurance on services utilization in the United States, while Sharanbekyan [21] focuses on family income and household size. These authors find a positive effect of insurance after correction for endogeneity. Jütting [4] shows that membership of mutual health insurance increases the probability of using health services and members pay, on average, less than half the amount paid by non-members when they need care. In this paper, we follow Meer and Rosen [11] in usingthe employment status as an instrument to identify the effect of insurance oh health care utilization.

\section{Data and Methodology}

\section{Data}

The data used in this study comes from the 2016 South African Demographic and Health Survey (SADHS), which is the most recent and largest nationally representative health survey that is publicly available in South Africa. Our 
Citation: Ouédraogo E, Dembélé A, Bationo JL (2021) Impact of Hospitalization and Dental Insurances on the Health Care Utilization in South Africa. J Healthcare 4(1):77-83

Table 1: Individuals' characteristics $(n=13883)$.

\begin{tabular}{|l|l|l|l|l|}
\hline Variables & Mean & Std. Err & Min & Max \\
\hline Dental insurance & 0.172 & 0.041 & 0 & 1 \\
\hline Hospitalization insurance & 0.386 & 0.112 & 0 & 1 \\
\hline Education level & & & & \\
\hline No Education & 0.137 & 0.020 & 0 & 1 \\
\hline Primary & 0.137 & 0.051 & 0 & 1 \\
\hline Secondary or more & 0.289 & 0.095 & 0 & 1 \\
\hline Married & 0.574 & 0.135 & 0 & 1 \\
\hline Age & 0.692 & 0.311 & 0 & 1 \\
\hline Household wealth index & 31.838 & 9.442 & 15 & 49 \\
\hline Poorer & & & & 1 \\
\hline Middle & 0.170 & 0.384 & 0 & 1 \\
\hline Richer & 0.191 & 0.393 & 0 & 1 \\
\hline Richest & 0.220 & 0.407 & 0 & 1 \\
\hline Urban resident & 0.241 & 0.433 & 0 & \\
\hline
\end{tabular}

Table 2: Health care services use $(n=13883)$.

\begin{tabular}{|l|l|l|}
\hline & Insurance & No Insurance \\
\hline Dental insurance & $\mathbf{( n = 2 3 8 8 )}$ & ( $\mathbf{n} \mathbf{1 1 4 9 5 )}$ \\
\hline At least one visit to the dentist & $51.1 \%$ & $\mathbf{2 3 . 6 \%}$ \\
\hline Number of visits to the dentist & 1.5092 & 0.8495 \\
\hline Hospitalisation insurance & $\mathbf{( n = 5 3 5 9 )}$ & $\mathbf{( n = 8 5 2 4 )}$ \\
\hline At least one night in the hospital & $18.2 \%$ & $16.4 \%$ \\
\hline Number of nights in hospital & 0.5110 & 0.5446 \\
\hline
\end{tabular}

final sample consists of 13,883 individuals. Table 1 presents the descriptive statistics of the sample. The results indicate that around $17.2 \%$ of individuals in our sample possess a dental insurance while this figure is $38.6 \%$ for hospitalization insurance. More than half (57.6\%) of the individuals have at least a secondary education level while $69.2 \%$ of them are married. Age is comprised between 15 and 49 with an average at almost 32. Men account for 44.86 percent and the average household size is 2.32 . Most respondents (57.4) have at least a secondary education and the self-employed represent 17.3 percent. Regarding healthcare services use, the results in Table 2 suggest that $11.1 \%$ of individuals with a dental insurance have visited a dentist during the last 12 months while this figure is $23.6 \%$ for individuals without insurance representing a huge gap of 27.7 percentage points. For hospitalization, the results suggest that $18.2 \%$ of individuals with hospitalization insurance spent at list one night in a hospitalization room while this figure is $16.4 \%$ suggesting a smaller gap.

\section{Methods}

This section presents the strategy for identifying the effect of insurance coverage for a given medical service on policyholders' use of that same service. We are interested in dental, and hospitalization services. For each of these services, we consider two effects. The first is the impact of insurance on the probability to use the service during the last 12 months of the reference period. For this case, the dependent variable $Y_{i}$ will be a binary variable that takes 1 when the individual $i$ has used the service and 0 otherwise.

The probability of requesting the care is then written:

$$
\begin{aligned}
& p\left(Y_{i}=-\right)=p\left(Y_{i}>0\right) \\
& =p\left(\alpha_{0}+\alpha_{1} T_{i}+X_{i}^{\prime} \beta>0\right) \\
& =p\left(\varepsilon<\alpha_{0}+\alpha_{1} T_{i}+X_{i}^{\prime} \beta\right) \\
& =\phi\left(\alpha_{0}+\alpha_{1} T_{i}+X_{i}^{\prime} \beta\right)
\end{aligned}
$$

$X_{i}$ represents a vector of individual characteristics including age, gender, education, marital status.

$T_{i}$ is the treatment variable that takes 1 if the individual is insured and 0 otherwise. The second effect we are interested in is the impact of insurance on the number of times the service was used in the last 12 months of the reference period. We estimate a Poisson regression which is suitable 
for count data with the following conditional average:

$$
\lambda_{i}=\beta_{0}+\beta_{1} T_{i}+\beta_{3} X_{i}+\varepsilon_{i}
$$

However, to account for potential endogeneity in standard estimates, we incorporate instruments for insurance. Endogeneity may appear in the model when unobserved variables affect both the probability of purchasing insurance and the probability of seeking care.

To control for this endogeneity, we estimate the following equation as the probability to have an insurance:

$$
T_{i}=\left\{\begin{array}{c}
1 \text { if } S_{i}^{*}=Z_{i}^{\prime} \pi+\mu>0 \text { (insurance) } \\
0 \text { if } S_{i}^{*}=Z_{i}^{\prime} \pi+\mu<0 \text { (Noinsurance) }
\end{array}\right.
$$

where $Z_{i}$ includes all of the factors that affect the decision to get a health insurance.

The probability to being insured can then be written as follows:

$$
\begin{aligned}
& P\left(Y_{i}=\frac{1}{X_{i}}\right)=p\left(S_{i}^{*}>0\right) \\
& =P\left(Z_{i}^{\prime} \pi+\mu>0\right) \\
& =P\left(\mu<Z_{i}^{\prime} \pi\right) \\
& =\phi\left(Z_{i}^{\prime} \pi\right)
\end{aligned}
$$

where $\Phi($.$) is the normal distribution. This are estimated$ using a maximum likelihood. To deal with the potential clustering of observations at the neighborhood level, the model is estimated using heteroskedasticity robust standard errors. To conduct the interpretations, the marginal effects are estimated and reported.

\section{Results and Discussion}

We are interested in how the utilization of a medical service depends on health insurance that covers such a service. Two types of services will be discussed: dental services and hospitalization services.

\section{Validity of employment status as an instrument for insurance status}

We first analyze the validity of employment status as an instrument for insurance status. The results of the first stage estimation of Equation (2) are presented in Table 3. The strength of the instruments is tested using the Stock and Yogo criteria. For dental insurance, The Cragg-Donald Wald $\mathrm{F}$ statistic (61.737) and the Kleibergen-Paaprk Wald F statistic (58.390) are both higher than the critical values of the StockYogo weak ID test at any level suggesting that our instrument is not weak. We also performed the under-identification test using the Kleibergen-Paaprk LM statistic which also rejected the under-identification hypothesis. Indeed, we find that being employed is positively associated (10.3\%) with the probability of having a dental of insurance. Similar results are observed for hospitalization insurance. The Cragg-Donald Wald F statistic (122.18) and the Kleibergen-Paaprk Wald F statistic (95.43) are both higher than the critical values of the Stock-Yogo weak ID test at any level as well. In fact, being employed increases the probability of insurance by $25.6 \%$.

\section{Effect of dental insurance}

The estimated marginal effects of dental insurance on

\begin{tabular}{|c|c|c|}
\hline & \multicolumn{2}{|c|}{$\begin{array}{l}\text { First-stage estimation } \\
\text { Dependent variable = Insured (yes/no) }\end{array}$} \\
\hline & Dental Insurance & Hospital Insurance \\
\hline \multirow[t]{2}{*}{ Working (base $=$ no) } & $0.103^{* * *}$ & $0.256^{* * *}$ \\
\hline & $(0.021)$ & $(0.004)$ \\
\hline age & yes & yes \\
\hline Household wealth index (base = poorest) & yes & yes \\
\hline Education & yes & yes \\
\hline Health indicator & yes & yes \\
\hline Body mass index & yes & yes \\
\hline Married & yes & yes \\
\hline Constant & yes & yes \\
\hline Observations & 13,883 & 13,883 \\
\hline Cragg-Donald Wald F statistic & 61.737 & 122.18 \\
\hline Kleibergen-Paaprk Wald F statistic & 58.390 & 95.43 \\
\hline
\end{tabular}
dental services use while controlling for the confounding factors is presented in Table 3. In these estimations we control for age, gender, education level, health status measured as the body mass index and the region of residence. Based on

Table 3: Validity of the instrument. 
Citation: Ouédraogo E, Dembélé A, Bationo JL (2021) Impact of Hospitalization and Dental Insurances on the Health Care Utilization in South Africa. J Healthcare 4(1):77-83

Table 4: Marginal effect of Dental Insurance on the probability of visiting a dentistand the number of visits.

\begin{tabular}{|c|c|c|c|c|}
\hline & \multicolumn{2}{|c|}{ Visited a dentist (yes/no) } & \multicolumn{2}{|c|}{ Number of visits to dentist } \\
\hline & Probit (dydx) & IVprobit-second stage (dydx) & OLS (dydx) & IV-second stage (dydx) \\
\hline \multirow[t]{2}{*}{ Dental Insurance } & $0.210^{* * *}$ & $0.402^{* * *}$ & $2.445^{* * *}$ & $4.685^{* * *}$ \\
\hline & $(0.021)$ & $(0.011)$ & $(0.046)$ & $(0.025)$ \\
\hline \multirow[t]{2}{*}{ age } & $0.023^{*}$ & $0.407^{* * *}$ & $0.022^{* *}$ & $0.017^{* * *}$ \\
\hline & $(0.017)$ & $(0.003)$ & $(0.002)$ & $(0.001)$ \\
\hline \multicolumn{5}{|c|}{ Household wealth index (base = poorest) } \\
\hline \multirow[t]{2}{*}{ Poorer } & 0.154 & -0.023 & 0.015 & 0.007 \\
\hline & $(0.052)$ & $(0.008)$ & $(0.018)$ & $(0.002)$ \\
\hline \multirow[t]{2}{*}{ middle } & 0.254 & -0.041 & 0.026 & 0.013 \\
\hline & $(0.574)$ & $(0.085)$ & $(0.058)$ & $(0.030)$ \\
\hline \multirow[t]{2}{*}{ Richer } & 0.437 & $0.075^{*}$ & 0.048 & 0.027 \\
\hline & $(0.056)$ & $(0.035)$ & $(0.061)$ & $(0.032)$ \\
\hline \multirow[t]{2}{*}{ Richest } & $0.20^{* * *}$ & $0.251^{* * *}$ & $0.119^{* * *}$ & $0.081^{* * *}$ \\
\hline & $(0.021)$ & $(0.013)$ & $(0.008)$ & $(0.012)$ \\
\hline \multicolumn{5}{|c|}{ Education level (Base = no education) } \\
\hline \multirow[t]{2}{*}{ Primary } & 0.511 & 0.113 & 0.072 & 0.041 \\
\hline & $(0.071)$ & $(0.009)$ & $(0.007)$ & $(0.003)$ \\
\hline \multirow[t]{2}{*}{ Secondary or higher } & 0.355 & $0.380^{* *}$ & $0.189^{* *}$ & $0.791^{* * *}$ \\
\hline & $(0.371)$ & $(0.009)$ & $(0.060)$ & $(0.011)$ \\
\hline \multicolumn{5}{|l|}{ Health indicator } \\
\hline \multirow[t]{2}{*}{ Body mass index } & 0.035 & $0.380^{* * *}$ & 0.189 & 0.191 \\
\hline & $(0.045)$ & (0.159) & $(0.763)$ & $(0.101)$ \\
\hline \multirow[t]{2}{*}{ Married } & 0.192 & 0.036 & 0.019 & 0.017 \\
\hline & $(0.067)$ & $(0.010)$ & $(0.005)$ & $(0.044)$ \\
\hline \multirow[t]{2}{*}{ Urban residence } & $0.038^{* * *}$ & $0.052^{* * *}$ & $0.155^{* * *}$ & $-0.276^{* * *}$ \\
\hline & $(0.034)$ & $(0.006)$ & $(0.004)$ & $(0.010)$ \\
\hline \multirow[t]{2}{*}{ Constant } & $0.133^{* * *}$ & $-0.024^{* * *}$ & $0.042^{* * *}$ & $0.045^{* * *}$ \\
\hline & $(0.037)$ & $(0.005)$ & $(0.012)$ & $(0.002)$ \\
\hline Observations & 13,883 & 13,883 & 13,883 & 13,883 \\
\hline
\end{tabular}

Robust standard errors in parentheses.

${ }^{* * *}: p<0.01,{ }^{* *}: p<0.05,{ }^{*}: p<0.1$.

the standard Probit regression (Table 4, column 1), the results show that having an insurance policy increases the likelihood of seeking the services of a dental specialist. In fact, holding a dental insurance policy increases the probability of visiting a dentist by 21 percent. However, this effect might be biased as discussed previously. Since being insured is likely be endogenous, we applied an instrumental variable method to better assess the effect of insurance.

Results of the IV estimation show that the effect of insurance on the use of dental care services is positive and significant. Indeed, insurance coverage for dental services increases the likelihood of a visit to a dental professional by 40.2 percent. Thus, we find that the magnitude of the effect by instrumental variables is higher than that obtained without controlling for endogeneity. Regarding frequency of use, the result from a standard Poisson regression shows a positive and significant effect of dental insurance on visits to a dental professional Instead, the IV results show a greater increase in the number of visits to the dentist by 2.4. Thus, the average household makes a double more visits to the dentist when they have dental insurance. When corrected for the endogeneity of having the insurancethe impact of insurance become 4.68. Thus, on average, individuals with dental insurance will make almost five timemore visits to the dentist than those who do not have dental insurance.

\section{Effect of hospital insurance}

In this section, we estimate the effect of an insurance covering hospitalization charges on the probability to spend a night at the hospital and the impact on the number of nights spent in hospital. In these estimations, we also control for age, gender, education level, health status measured as the 
Citation: Ouédraogo E, Dembélé A, Bationo JL (2021) Impact of Hospitalization and Dental Insurances on the Health Care Utilization in South Africa. J Healthcare 4(1):77-83

Table 5: Marginal effect of Hospital Insurance on the probability of being hospitalized and the number of days of hospitalization.

\begin{tabular}{|c|c|c|c|c|}
\hline & \multicolumn{2}{|c|}{ Hospitalized (yes/no) } & \multicolumn{2}{|c|}{ Number of days of hospitalization } \\
\hline & Probit & IVprobit-second stage & OLS & IV-second stage \\
\hline \multirow[t]{2}{*}{ Hospital Insurance } & -0.068 & $-0.032^{* * *}$ & $-2,664$ & $-7.542^{* * *}$ \\
\hline & (0.009) & $(0.062)$ & $(0.027)$ & $(0.044)$ \\
\hline \multirow[t]{2}{*}{ age } & $0.060^{* * *}$ & $0.098^{* * *}$ & $0.012^{* * *}$ & $0.019^{* * *}$ \\
\hline & $(0.036)$ & $(0.180)$ & $(0.003)$ & $(0.004)$ \\
\hline \multicolumn{5}{|c|}{ Household wealth index (base $=$ poorest) } \\
\hline \multirow[t]{2}{*}{ Poorer } & -0.022 & 0.980 & -0.006 & 0.995 \\
\hline & $(0.014)$ & $(0.015)$ & $(0.016)$ & $(0.003)$ \\
\hline \multirow[t]{2}{*}{ middle } & $0.042^{* * *}$ & $0.959^{* * *}$ & 0.055 & $0.134^{* *}$ \\
\hline & $(0.014)$ & $(0.014)$ & $(0.010)$ & $(0.005)$ \\
\hline \multirow[t]{2}{*}{ Richer } & $0.0670^{* * *}$ & $0.935^{* * *}$ & $0.001^{* * *}$ & $0.892^{* * *}$ \\
\hline & (0.015) & $(0.014)$ & $(0.012)$ & $(0.001)$ \\
\hline \multirow[t]{2}{*}{ Richest } & $0.752^{* *}$ & $0.851^{* * *}$ & $0.045^{* *}$ & $0.677^{* * *}$ \\
\hline & $(0.020)$ & $(0.017)$ & $(0.004)$ & $(0.016)$ \\
\hline \multicolumn{5}{|c|}{ Education level (Base = no education) } \\
\hline \multirow[t]{2}{*}{ Primary } & $0.0404^{* *}$ & $0.965^{* * *}$ & 0.001 & 0.999 \\
\hline & $(0.016)$ & $(0.012)$ & $(0.002)$ & $(0.231)$ \\
\hline \multirow[t]{2}{*}{ Secondary or higher } & 0.0616 & $0.823^{* * *}$ & 0.0172 & 1.017 \\
\hline & $(0.046)$ & $(0.018)$ & $(0.005)$ & $(0.025)$ \\
\hline \multicolumn{5}{|l|}{ Health indicator } \\
\hline \multirow[t]{2}{*}{ Body mass index } & $0.118^{* * *}$ & $1.125^{* * *}$ & $1.208^{* * *}$ & $1.898^{* * *}$ \\
\hline & $(0.009)$ & $(0.010)$ & $(0.002)$ & $(0.022)$ \\
\hline \multirow[t]{2}{*}{ Married } & $0.0923^{*}$ & $1.097^{*}$ & 0.018 & 0.992 \\
\hline & $(0.039)$ & $(0.043)$ & $(0.006)$ & $(0.006)$ \\
\hline \multirow[t]{2}{*}{ Urban residence } & $0.069^{*}$ & $1.072^{* * *}$ & $0.002^{*}$ & $1.006^{* * *}$ \\
\hline & $(0.011)$ & $(0.012)$ & $(0.003)$ & $(0.003)$ \\
\hline \multirow[t]{2}{*}{ Constant } & $-0.709^{* * *}$ & $0.492^{* * *}$ & $3.019^{* * *}$ & $2.472^{* * *}$ \\
\hline & $(0.062)$ & $(0.031)$ & $(0.011)$ & $(0.218)$ \\
\hline Observations & 13,883 & 13,883 & 13,883 & 13,883 \\
\hline
\end{tabular}

Robust standard errors in parentheses.

${ }^{* * *}: p<0.01,{ }^{* *}: p<0.05,{ }^{*}: p<0.1$.

body mass index and the region of residence. The results from the standard probit model suggest that insurance does not affect the probability to spend a night at the hospital (Table 5, column 1). However, when we control for the endogeneity issues using the IV estimation, we find that the effect is significant at the 1 percent threshold. In fact, having insurance covering hospitalization charges reduces the probability of spending a night in hospital by 3.19 percent (Table 4, column 2).

When analyzing the effect of this insurance on the number of nights spent in hospital, we find that the effect is not statistically significant when we do not consider the possible endogeneity of the insurance (Table 5 , column 3 ). When estimating with an instrumental variable's method, we find that insurance covering hospital charges reduces the number of nights spent in hospital. In fact, the average individual spends 7.54 fewer nights in hospital when he has insurance covering hospital charges (Table 4, column 4). Despite being counterintuitive, this result is very similar to some in the literature $[18,22]$. In fact, the decision to visit a health professional is an individual decision. However, the need for hospitalization is usually decided by health professionals after diagnosis. Another plausible explanation is that insured 
persons may be treated more intensively. This could speed up recovery and thus reduce the number of nights spent in hospital [22]. In an empirical application, Hullegie and Klein Hullegie and Klein [18] find the same negative effect in Germany.

\section{Conclusion}

This paper shed light on the impact of dental and hospital insurance on the use of medical services. Since the choice to be insured is endogenous, we used an instrumental variable method to capture the influence of insurance. After controlling for endogeneity, the results show that dental insurance increases the probability of consulting by 40.21 percent. Hospital insurance reduces the probability of spending at least one night in hospital by 3.19 percent. Furthermore, our results suggest that individuals tend to increase the number of visits to the dental professional by 4.68 when they have dental insurance but spend less nights (7.54 night) in hospital if they have hospitalization insurance. The positive impact of dental insurance is consistent with theoretical expectations and the empirical literature [4,20-22]. Moreover, the positive impact of hospital insurance confirms the empirical work of Hullegie and Klein [18] and Manning, et al. [22] who find the same negative effect of hospitalization insurance.

Therefore, in order to design an effective healthcare system, policy makers and health care programmers in South Africa should improve individuals' access to both insurances to promote the use of these specific health services in South Africa. An interesting avenue for future research is to extend this study to other types of insurances in Sub-Saharan Africa. Implementing an experimental setting can also help to measure and use individuals' preferences as preferences and time preferences as potential confounders.

\section{Consent}

As per international standard or university standard, respondents' written consent has been collected and preserved by the author(s).

\section{Competing Interests}

Authors have declared that no competing interests exist.

\section{References}

1. Ataguba JEO, Goudge J (2012) The impact of health insurance on healthcareutilization and out-of-pocket payments in South Africa. The Geneva papers on risk and insurance-issues and practice 37: 633-654.

2. Newhouse JP (1978) The economics of medical care: A policy perspective.

3. Phelps ES (2009) Rewarding work: How to restore participation and self-support to free enterprise. Harvard University Press.

4. Jütting JP (2004) Do community-based health insurance schemes improve poor people's access to healthcare? Evidence from rural Senegal. World development 32: 273-288.

5. Ataguba JEO, Goudge J (2012) The impact of health insurance on healthcareutilization and out-of-pocket payments in South Africa. The Geneva Papers on Risk and Insurance-Issues and
Practice 37: 633-654

6. Spaan E, Mathijssen J, Tromp N, et al. (2012) The impact of health insurance in Africa and Asia: A systematic review. Bull World Health Organ 90: 685-692.

7. Buchmueller TC, Couffinhal A, Grignon M, et al. (2004) Access to physician services: Does supplemental insurance matter? evidence from France. Health economics 13: 669-687.

8. Albouy V, Crépon B (2007) Aléa moral en santé: Une évaluation dans le cadre du modèle causal de Rubin. Document de travail de la Direction des études et synthèses économiques de l'Insee 12 .

9. De Allegri M, Sanon M, Sauerborn R (2006) To enroll or not to enroll?: A qualitative investigation of demand for health insurance in rural West Africa. Social science \& medicine 62:1520-1527.

10. Ma X, Cen $Y$ (2017) Public health insurance system reform and its impact on health service utilization in Rural China: Evidence from CHNS 2000 and 2011. Chinese Studies 6: 85-107.

11. Meer J, Rosen HS (2004) Insurance and the utilization of medical services. Social Science \& Medicine 58:1623-1632.

12. Li X, Zhang W (2013) The impacts of health insurance on health care utilization among the older people in China. Social Science \& Medicine 85: 59-65.

13. Ndongo JC A, Nanfosso RT (2012) Impact des Mutuelles de santé sur les Comportements de Demande de Santé des Ménages au Cameroun.

14. Card D, Dobkin C, Maestas N (2004) The impact of nearly universal coverage on health care utilization and health: Evidence from Medicare. American Economic Review 98: 2242-2258.

15. Finkelstein A, McKnight R (2005) What did Medicare do (and was it worth it)? Natl Bur Econ Res Work Pap 11609.

16. Polsky D, Doshi JA, Escarce J, et al. (2009) The health effects of Medicare for the near-elderly uninsured. Health Serv Res 44: 926-945.

17. Koch S, Alaba O (2010) On health insurance and household decisions: A treatment effect analysis. Social Science \& Medicine 70: 175-182.

18. Hullegie P, Klein TJ (2010) The effect of private health insurance on medical care utilization and self-assessed health in Germany. Health economics 19:1048-1062.

19. Zounmenou AY (2017) Assurance maladie et utilisation des services de santé au benin (Doctoral dissertation, De L'université D’Abomey-Calavi (BENIN)).

20. El Omari S (2007) Évaluation des impacts de l'assurance sociale maladie sur la consommation des soins de santé par la population rurale à faible revenu aux Philippines.

21. Sharanbekyan A (2012) The impact of health insurance on health care utilization: Case study for armenia.

22. Manning WG, Morris CN, Newhouse JP, et al. (1981) A twopart model of the demand for medical care: Preliminary results from the health insurance study. Health, Economics, and Health Economics 103-123. 